\title{
Laryngeal air column width ratio in predicting post extubation stridor
}

\author{
Pradeep M. Venkategowda, Kranthi Mahendrakar, S. Manimala Rao, Dnyaneshwar P. Mutkule, \\ Chetan G. Shirodkar, H. Yogesh
}

Aim: Correlation of upper air column width ratio in postextubation stridor patients. Materials and Methods: A prospective observational study was conducted in a tertiary hospital between January and December 2013. Patients who were admitted in Intensive Care Unit and intubated for $>24 \mathrm{~h}$ were included (72 patients). The upper airway air column width ratio (air column width before extubation/air column width after intubation) was calculated and compared in patient with or without postextubation stridor. Results: The incidence of stridor was $6.9 \%$ (5/72). The duration of mechanical ventilation was $5.60 \pm 1.14$ days and 3.91 \pm 1.45 days in stridor and nonstridor group respectively. In all 5 patients who had stridor, the upper airway air column width ratio was 0.8 or less. Conclusion: Air column width ratio of 0.8 or less may be helpful in predicting postextubation stridor, which should be confirmed by large observational studies.

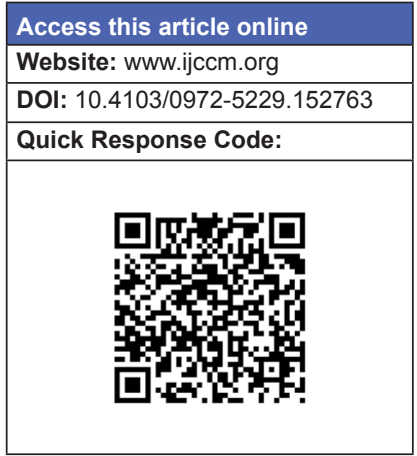

Keywords: Air column width, cricothyroid membrane, cuff leak test, postextubation stridor, ultrasound

\section{Introduction}

Endotracheal intubation can cause damage to the oropharynx, larynx, and trachea. Mucosal ulcerations and laryngeal edema occur in almost all patients intubated for 4 days or more. ${ }^{[1]}$ Postextubation stridor may occur in $2-15 \%$ of patients after extubation. ${ }^{[2,3]}$ Stridor involves a higher degree of morbidity and mortality particularly those who requires re-intubation. ${ }^{[4]}$ Examination of the vocal cords (VC) is most commonly performed by direct or indirect laryngoscopy, but this may not be readily approached in intubated patients. Postextubation stridor is commonly the result of edema of the subglottic area or the VC. ${ }^{[5]}$ The cuff-leak test, which has been used widely in the evaluation of upper-airway patency prior to extubation, but its positive predictive value is still low. ${ }^{[6]}$ There is no single test with high positive predictive

\section{From:}

Department of Critical Care Medicine, Yashoda Multi-Speciality Hospital,

Shantishikara Apartments, D4, \#124, Bedind Enadu Bld, Somajiguda,

Hyderabad, India

\section{Correspondence:}

Dr. S. Manimala Rao, Department of Critical Care Medicine,

Yashoda Multi-Speciality Hospital, Somajiguda, Hyderabad, India.

E-mail: manimalarao@ hotmail.com value to identify the patients who are at risk of laryngeal edema and postextubation stridor.

Noninvasive approaches to examine the $\mathrm{VC}$ and the larynx would be helpful and there have been many ultra-sonographical methods developed for visualizing this structure..$^{[7-13]}$

\section{Materials and Methods}

After taking informed consent from patient relatives and approval from hospital scientific review board, patients between age 18 and 75 years who were admitted in Intensive Care Unit during 1-year study period and intubated for $>24 \mathrm{~h}$ were included (72 patients). All patients were intubated (high-volume, low-pressure) with cuffed endotracheal tube (ETT) (with an internal diameter size of 7.0-7.5 $\mathrm{mm}$ for females and $8.0-8.5 \mathrm{~mm}$ for males). Laryngeal ultrasound (US) was performed with a $5.0 \mathrm{MHz}$ linear probe to measure air column width (defined as the width of air passed through the VC as determined by US) in all these patients as shown in Figure 1 . Air column width was measured with the probe placed on the cricothyroid membrane with a transverse 
view of the larynx and patient positioned supine with a neck extended and ETT cuff deflated which was taken as control [Figure 2]. 3-4 h before planned extubation laryngeal US was repeated, and measurement recorded as test [Figure 3]. We have recorded the air-column width with cuff deflated over the respiratory cycles for three consecutive times, and the average value was considered. The cuff-leak test was performed as described by Miller and Cole. ${ }^{[14]}$ All of the patients were extubated when the cuff-leak was $>100 \mathrm{ml}$ and when they passed weaning trial. Stridor was defined as the presence of a high-pitched inspiratory wheeze localized to the trachea or the larynx and associated with respiratory distress, usually requiring medical intervention.

Statistical analyses were performed using standard statistical software. Categorical variables were summarized through the calculation of frequency and relative frequency. Continuous variables were summarized through the calculation of mean and standard error.

\section{Results}

Theincidence of stridor in our study was $6.9 \%$ (5/72). The duration of mechanical ventilation was $5.60 \pm 1.14$ days and $3.91 \pm 1.45$ days in stridor and nonstridor group, respectively [Table 1]. All 72 patients were extubated when cuff leak was $>100 \mathrm{ml}$. The average volume of cuff leak in stridor and nonstridor group was $112.0 \pm 10.36 \mathrm{ml}$ and $191.34 \pm 54.00 \mathrm{ml}$ respectively. The mean air column width in stridor group after intubation (cuff deflation) was $5.98 \pm 0.19 \mathrm{~mm}$ and before extubation (cuff deflation) was $4.46 \pm 0.20 \mathrm{~mm}$. The mean air column width in nonstridor group after intubation (cuff deflation) was $6.01 \pm 0.38 \mathrm{~mm}$ and before extubation (cuff deflation) was $5.64 \pm 0.38 \mathrm{~mm}$. The air column width ratio (before extubation/after intubation) in stridor and nonstridor groups were $0.74 \pm 0.04 \mathrm{~mm}$ and $0.93 \pm 0.02 \mathrm{~mm}$ respectively. In our study 5 patients with an air column width ratio of 0.8 or less had postextubation stridor even with standard cuff leak test volume of $>100 \mathrm{ml}$. Out of 5 patients who had stridor 4 patients were re intubated as they did not respond to steroids, epinephrine nebulisation and bilevel positive airway pressure support.

\section{Discussion}

Endotracheal intubation and mechanical ventilation is commonly performed for hypoxic patients secondary to respiratory or cardiac cause. Mucosal ulcerations and laryngeal edema occur in almost all patients intubated for 4 days or more. ${ }^{[1]}$ Postextubation stridor may occur

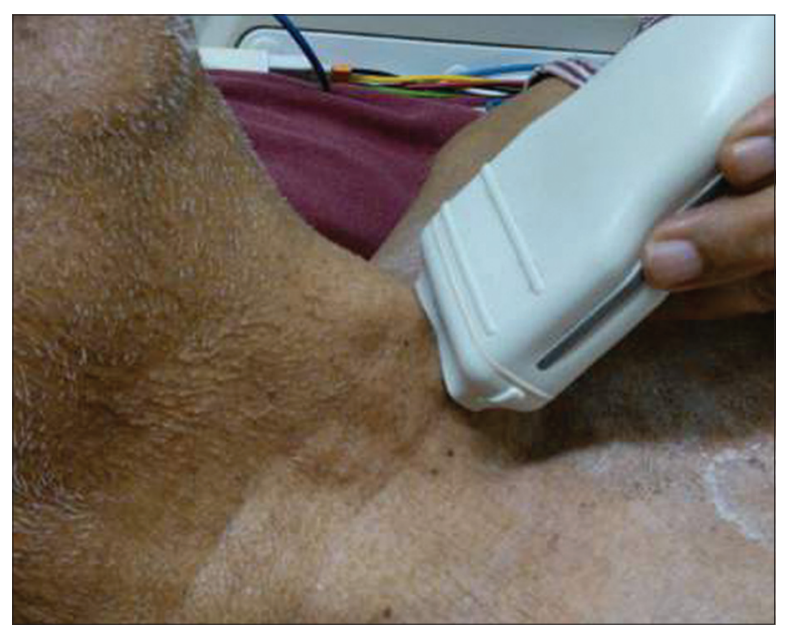

Figure I: Performing laryngeal ultrasound in intubated patient at the level of cricothyroid

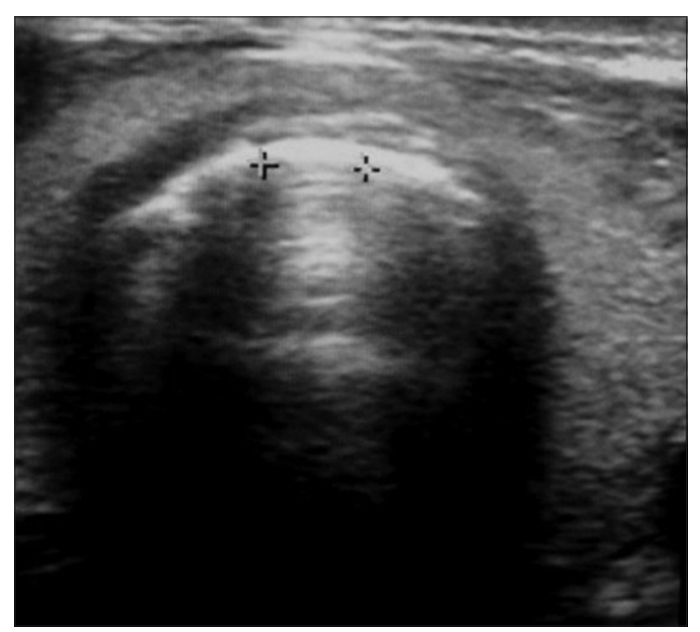

Figure 2: Air column width $(0.57 \mathrm{~cm})$ immediately after intubation with cuff deflated

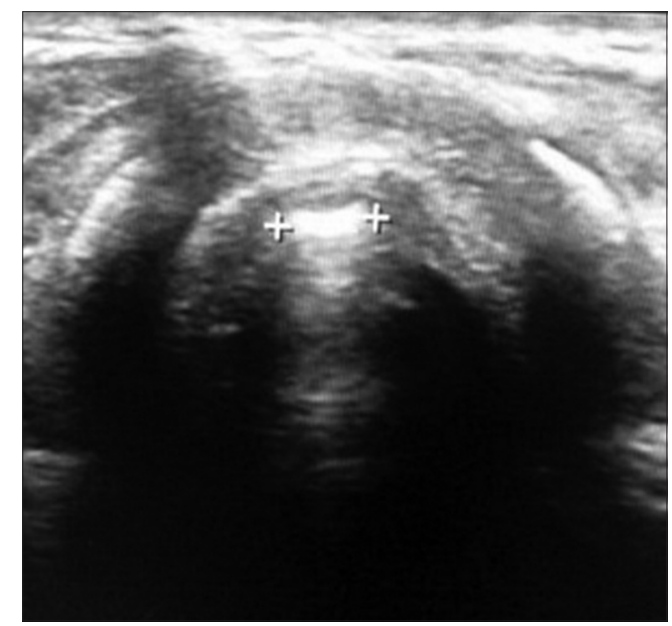

Figure 3: Air column width $(0.42 \mathrm{~cm})$ of same patient $3 \mathrm{~h}$ before extubation with cuff deflated and the air column width ratio of 0.73 . This patient had stridor after extubation

in $2-15 \%$ of patients after extubation. ${ }^{[2,3]}$ Stridor involves a higher degree of morbidity and mortality particularly 
Table I: Characteristics of patients with and without stridor

\begin{tabular}{lcc}
\hline & \multicolumn{2}{c}{ Mean \pm SD } \\
\cline { 2 - 3 } & $\begin{array}{c}\text { Nonstridor } \\
(\boldsymbol{n}=67)\end{array}$ & $\begin{array}{c}\text { Stridor } \\
(\boldsymbol{n}=\mathbf{5})\end{array}$ \\
\hline Age (average) & $54 \pm$ years & $55 \pm$ years \\
Sex & 35 & \\
$\quad$ Males & 32 & 2 \\
$\quad$ Females & & 3 \\
ETT size & 12 & 1 \\
$7.0 \mathrm{~mm}$ & 20 & 2 \\
$7.5 \mathrm{~mm}$ & 14 & 1 \\
$8.0 \mathrm{~mm}$ & 21 & 1 \\
$8.5 \mathrm{~mm}$ & $3.91 \pm 1.45$ & $5.60 \pm 1.14$ \\
Duration of mechanical ventilation (days) & $214.25 \pm 44.83$ & $172.0 \pm 22.80$ \\
Cuff leak after intubation (ml) & $191.34 \pm 54.0$ & $112.0 \pm 10.36$ \\
Cuff leak before extubation (ml) & $6.01 \pm 0.38$ & $5.98 \pm 0.19$ \\
Air column width (after intubation) (mm) & $5.64 \pm 0.38$ & $4.46 \pm 0.20$ \\
Air column width (before extubation) $(\mathrm{mm})$ & $0.93 \pm 0.02$ & $0.74 \pm 0.04$ \\
Air column width ratio (mm) & &
\end{tabular}

SD: Standard deviation; ETT: Endotracheal tube

those who requires re-intubation. ${ }^{[4]}$ The cuff-leak test, which has been used widely in the evaluation of upper-airway patency prior to extubation, but its positive predictive value is still low. ${ }^{[6]}$ Critical care physicians can easily evaluate the weaning potential in intubated patients, but it is difficult to predict the extubation failure due to upper-airway obstruction. Laryngeal US is a new, less invasive and easily reproducible method of examining the larynx. Many ultra-sonographical methods were developed for visualizing this structure $e^{[-13]}$ in the recent years. Miller and Cole ${ }^{[14]}$ have shown that patients with reduced cuff leak volume $(<110 \mathrm{ml})$ prior to extubation are at increased risk for postextubation stridor. The air column width measured by US has a potential ability to predict postextubation stridor in intubated patients. This prospective study was carried to correlate upper air column width ratio in postextubation stridor patients.

The standard ETT cuff leak test was performed before extubation and patients were extubated when cuff leak of $100 \mathrm{ml}$ or more and who fulfilled the weaning criteria. Cuff leak test values and upper airway air column width ratio (air column width before extubation/air column width after intubation) were analyzed at the end of the study.

The incidence of stridor in our study was $6.9 \%(5 / 72)$, which is similar to other studies ${ }^{[2,3]}(2-15 \%)$. There was a correlation between stridor and number of intubation days (the duration of mechanical ventilation was $5.60 \pm 1.14$ days and $3.91 \pm 1.45$ days in stridor and nonstridor group respectively), which has also been shown by Kastanos et al. ${ }^{[15]}$ Ding et al. ${ }^{[16]}$ have shown that laryngeal ultrasonography could be reliable noninvasive method in identifying laryngeal edema and to predict postextubation stridor. In our study, patients with upper airway air column width ratio of 0.8 or less had postextubation stridor even with standard cuff leak test of $>100 \mathrm{ml}$. Laryngeal US can be used in prediction of postextubation stridor, which has high sensitivity and specificity. In our study, of 72 patients, only 5 patients had stridor which is very low compared with the nonstridor group and to recommend as the definitive test to predict postextubation stridor. Large study populations are required for further correlation of our findings.

\section{Conclusion}

Air column width ratio of 0.8 or less may be helpful in predicting postextubation stridor, which should be confirmed by large observational studies.

\section{Acknowledgments}

We gratefully acknowledge Radiologists (Prof and HOD), Respiratory therapists, nurses and management of the hospital for their valuable support.

\section{References}

1. Epstein SK, Ciubotaru RL. Independent effects of etiology of failure and time to reintubation on outcome for patients failing extubation. Am J Respir Crit Care Med 1998;158:489-93.

2. Rashkin MC, Davis T. Acute complications of endotracheal intubation. Relationship to reintubation, route, urgency, and duration. Chest 1986;89:165-7.

3. Colice GL, Stukel TA, Dain B. Laryngeal complications of prolonged intubation. Chest 1989;96:877-84

4. Torres A, Gatell JM, Aznar E, el-Ebiary M, Puig de la Bellacasa J, González J, et al. Re-intubation increases the risk of nosocomial pneumonia in patients needing mechanical ventilation. Am J Respir Crit Care Med 1995;152:137-41.

5. Benjamin B. Prolonged intubation injuries of the larynx: Endoscopic diagnosis, classification, and treatment. Ann Otol Rhinol Laryngol Suppl 1993;160:1-15.

6. Engoren M. Evaluation of the cuff-leak test in a cardiac surgery population. Chest 1999;116:1029-31.

7. Hertz CH, Lindström K, Sonesson B. Ultrasonic recording of the vibrating vocal folds. A preliminary report. Acta Otolaryngol 1970;69:223-30.

8. Miles KA. Ultrasound demonstration of vocal cord movements. Br J Radiol 1989;62:871-2.

9. Raghavendra BN, Horii SC, Reede DL, Rumancik WM, Persky M, Bergeron T. Sonographic anatomy of the larynx, with particular reference to the vocal cords. J Ultrasound Med 1987;6:225-30.

10. Ueda D, Yano K, Okuno A. Ultrasonic imaging of the tongue, mouth, and vocal cords in normal children: Establishment of basic scanning positions. J Clin Ultrasound 1993;21:431-9.

11. Carp H, Bundy A. A preliminary study of the ultrasound examination of the vocal cords and larynx. Anesth Analg 1992;75:639-40.

12. Garel C, Contencin P, Polonovski JM, Hassan M, Narcy P. Laryngeal ultrasonography in infants and children: A new way of investigating. Normal and pathological findings. Int J Pediatr Otorhinolaryngol 1992;23:107-15.

13. Shih JY, Lee LN, Wu HD, Yu CJ, Wang HC, Chang YL, et al. Sonographic imaging of the trachea. J Ultrasound Med 1997;16:783-90. 
14. Miller RL, Cole RP. Association between reduced cuff leak volume and postextubation stridor. Chest 1996;110:1035-40.

15. Kastanos N, Estopá Miró R, Marín Perez A, Xaubet Mir A, Agustí-Vidal A. Laryngotracheal injury due to endotracheal intubation: Incidence, evolution, and predisposing factors. A prospective long-term study. Crit Care Med 1983;11:362-7.

16. Ding LW, Wang HC, Wu HD, Chang CJ, Yang PC. Laryngeal ultrasound: A useful method in predicting post-extubation stridor A pilot study. Eur Respir J 2006;27:384-9.

How to cite this article: Venkategowda PM, Mahendrakar K, Rao SM, Mutkule DP, Shirodkar CG, Yogesh H. Laryngeal air column width ratio in predicting post extubation stridor. Indian J Crit Care Med 2015;19:170-3.

Source of Support: Nil, Conflict of Interest: None declared. 